\title{
FIRST CONFIRMATION OF BORDETELLA PERTUSSIS OCCURRENCE IN SLOVAKIA BY USING REAL-TIME PCR
}

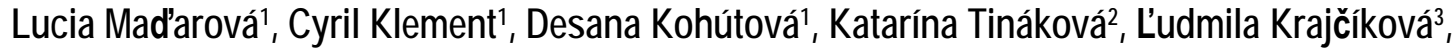 \\ Margita Obernauerová ${ }^{4}$ \\ ${ }^{1}$ Regional Authority of Public Health Banská Bystrica, Division of Medical Microbiology, Banská Bystrica, Slovak Republic \\ ${ }^{2}$ Regional Authority of Public Health Nitra, Division of Epidemiology, Nitra, Slovak Republic \\ ${ }^{3}$ Regional Authority of Public Health Topol'čany, Division of Epidemiology, Topolčany, Slovak Republic \\ ${ }^{4}$ Faculty of Natural Sciences, Comenius University, Department of Microbiology and Virology, Bratislava, Slovak Republic
}

\section{SUMMARY}

By application of the real-time PCR we manage to confirm the diagnosis and occurrence of a disease, which is caused by Bordetella pertussis - pertussis. Using this method we have proven the presence of DNA of Bordetella pertussis in the biological materials (nasopharyngeal swabs). The presence of IS481 genome sequence of Bordetella pertussis was confirmed. This method of detection of pathogens seems to be very rapid, simple, and specific. In the case of adequate technical laboratory equipment it may become very suitable and important supporter in explanation and confirmation of the occurrence of bacterial infections.

Key words: Bordetella pertussis, whooping cough, real-time PCR, LightCycler

Address for correspondence: C. Klement, Regional Authority of Public Health, Banská Bystrica, Division of Medical Microbiology, Cesta knemocnici 1, 97556 Banská Bystrica, Slovak Republic. E-mail: cyril.klement@vzbb.sk

\section{INTRODUCTION}

The application of knowledge of bacterial genetics is no longer a new issue and the domain of the research and development centres, but they are increasingly applied in microbiological practice. Using molecular-biology methods it is possible to confirm the clinical diagnosis, where other detection methods have failed.

Definitive diagnosis of causative organism in pertussis (whooping cough), Bordetella pertussis, is traditionally been made by culture of secretions from the nasopharynx (1).

Serological tests like CFT (Complement Fixation Test) or ELISA (Enzyne-linked Immunosorbent Assay) (detection of antibodies produced against a filamentous hemaglutinin or against pertussis toxin) are more sensitive than culture, but these usually provide late, or retrospective diagnosis only (2).

To overcome these limitations, detection of B. pertussis DNA from nasopharyngeal aspirates and swabs has been described using PCR assays (3, 4, 5, 6, 7, 8).

In 2001 Kösters at al. have developed a real-time PCR assay based on the TaqMan technology for detection of Bordetella pertussis in clinical samples (9). One year before Reischel et al. have described a real-time PCR technique for detection of Bordetella pertussis by using LightCycler instrument and fluorescent labelled probes (10). We use this method in our department for diagnosis of pertussis.

\section{MATERIALS AND METHODS}

\section{Material}

Samples: From December 2004 to the February 200533 nasopharyngeal swabs - taken from 29 patients from Nitra and Topol'čany, were examined. Dacron tampons were used because previous studies had shown that calcium alginate fiber and aluminium shaft components inhibited PCR reaction (11). Materials were delivered to the laboratory by a special courier.

First case suspected of Bordetella pertussis infection was a little boy from Nitra (Table 1) Nasopharyngeal swab was taken by epidemiologist from this boy, because the clinical symptoms indicated the presence of Bordetella pertussis. Next three swabs were taken from his brother (Table1) and two sisters, neighbours of these two boys (Table1). From one of these sisters there was taken next one swab with off-set (Table 1).

Table 1. Results of sample examination for B. pertussis - Nitra 2004

\begin{tabular}{|l|l|l|l|l|}
\hline $\begin{array}{l}\text { Number } \\
\text { of sample }\end{array}$ & Date of birth & $\begin{array}{l}\text { Date of } \\
\text { samples taking }\end{array}$ & $\begin{array}{l}\text { Date of } \\
\text { examination }\end{array}$ & Result \\
\hline $1 / 04$ & 01.05 .2004 & 08.12 .2004 & 15.12 .2004 & POSITIVE \\
\hline $2 / 04$ & 20.12 .1990 & 08.12 .2004 & 15.12 .2004 & NEGATIVE \\
\hline $3 / 04$ & 12.09 .1985 & 23.12 .2004 & 05.01 .2005 & POSITIVE \\
\hline $4 / 04^{\star}$ & 12.09 .1985 & 05.01 .2005 & 05.01 .2005 & POSITIVE \\
\hline $5 / 04$ & 07.01 .1991 & 05.01 .2005 & 05.01 .2005 & POSITIVE \\
\hline
\end{tabular}

* repeated taking of sample with off-set 
Table 2. Results of sample examination for B. pertussis - Topol'čany 2005

\begin{tabular}{|c|c|c|c|c|}
\hline $\begin{array}{c}\text { Number } \\
\text { of sample }\end{array}$ & Date of birth & $\begin{array}{c}\text { Date of } \\
\text { samples taking }\end{array}$ & $\begin{array}{c}\text { Date of } \\
\text { examination }\end{array}$ & Result \\
\hline $3 / 05$ & 26.11 .2004 & 20.01 .2005 & 21.01 .2005 & POSITIVE \\
\hline $4 / 05$ & 03.04 .1981 & 31.01 .2005 & 02.02 .2005 & POSITIVE \\
\hline $5 / 05$ & 16.04 .1942 & 31.01 .2005 & 02.02 .2005 & POSITIVE \\
\hline $8 / 05$ & 04.08 .1993 & 31.01 .2005 & 02.02 .2005 & NEGATIVE \\
\hline $9 / 05$ & 22.05 .1995 & 31.01 .2005 & 02.02 .2005 & POSITIVE \\
\hline $10 / 05$ & 15.03 .1978 & 31.01 .2005 & 02.02 .2005 & NEGATIVE \\
\hline $11 / 05$ & 11.12 .1982 & 31.01 .2005 & 02.02 .2005 & NEGATIVE \\
\hline $12 / 05$ & 15.04 .2003 & 31.01 .2005 & 02.02 .2005 & NEGATIVE \\
\hline $13 / 05$ & 30.09 .1954 & 31.01 .2005 & 02.02 .2005 & NEGATIVE \\
\hline $14 / 05$ & 05.07 .1951 & 31.01 .2005 & 02.02 .2005 & POSITIVE \\
\hline $15 / 05$ & 06.10 .1981 & 31.01 .2005 & 02.02 .2005 & NEGATIVE \\
\hline $16 / 05$ & 08.06 .1976 & 31.01 .2005 & 02.02 .2005 & POSITIVE \\
\hline $17 / 05$ & 01.03 .1973 & 31.01 .2005 & 02.02 .2005 & NEGATIVE \\
\hline $18 / 05$ & 16.05 .2001 & 31.01 .2005 & 02.02 .2005 & NEGATIVE \\
\hline $19 / 05$ & 09.01 .1983 & 31.01 .2005 & 02.02 .2005 & NEGATIVE \\
\hline $20 / 05$ & 25.12 .2004 & 31.01 .2005 & 02.02 .2005 & NEGATIVE \\
\hline $21 / 05 *$ & 26.11 .2004 & 31.01 .2005 & 02.02 .2005 & NEGATIVE \\
\hline $22 / 05$ & 24.01 .2000 & 31.01 .2005 & 02.02 .2005 & NEGATIVE \\
\hline $23 / 05$ & 09.02 .2004 & 31.01 .2005 & 02.02 .2005 & NEGATIVE \\
\hline $24 / 05$ & 04.09 .1962 & 31.01 .2005 & 02.02 .2005 & NEGATIVE \\
\hline $25 / 05$ & 17.081978 & 31.01 .2005 & 02.02 .2005 & NEGATIVE \\
\hline $26 / 05$ & 28.05 .1946 & 31.01 .2005 & 02.02 .2005 & DISPUTE \\
\hline
\end{tabular}

* repeated taking of sample with off-set

In January 2005 we have obtained a nasopharyngeal swab from a little boy who lived in Topol'čany (Table 2). When epidemiologists came to check the home of this boy and his mother, they found next to 20 people in bad hygienic conditions. There were 9 people in two-room flat and 11 people in oneroom flat. Therefore they took 20 nasopharyngeal swabs from them (Table 2), one repeated swab from a little boy (Table 2) and also two control swabs from themselves. These swabs we used as negative control of nucleic acid isolation (Table 3). At the time of taking samples epidemiologists did not have any clinical symptoms of pertussis.
Table 3. Control nasopharyngeal swabs from two epidemiologists, negative control of nucleic acid isolation

\begin{tabular}{|l|l|l|l|l|}
\hline $\begin{array}{l}\text { Number } \\
\text { of sample }\end{array}$ & Date of birth & $\begin{array}{l}\text { Date of samples } \\
\text { taking }\end{array}$ & $\begin{array}{l}\text { Date of } \\
\text { examination }\end{array}$ & Result \\
\hline $6 / 05$ & 30.06 .1970 & 31.01 .2005 & 02.02 .2005 & NEGATIVE \\
\hline $7 / 05$ & 30.10 .1962 & 31.01 .2005 & 02.02 .2005 & NEGATIVE \\
\hline
\end{tabular}

Table 4. Topol'čany 2005, later taking of samples

\begin{tabular}{|l|l|l|l|l|}
\hline $\begin{array}{l}\text { Number } \\
\text { of sample }\end{array}$ & Date of birth & $\begin{array}{l}\text { Date of } \\
\text { samples taking }\end{array}$ & $\begin{array}{l}\text { Date of } \\
\text { examination }\end{array}$ & Result \\
\hline $28 / 05$ & 11.12 .1993 & 15.02 .2005 & 01.03 .2005 & NEGATIVE \\
\hline $29 / 05^{*}$ & 25.12 .2004 & 15.02 .2005 & 01.03 .2005 & NEGATIVE \\
\hline $30 / 05^{*}$ & 15.04 .2003 & 15.02 .2005 & 01.03 .2005 & NEGATIVE \\
\hline $31 / 05$ & 11.04 .1956 & 15.02 .2005 & 01.03 .2005 & NEGATIVE \\
\hline $32 / 05$ & 22.12 .1960 & 15.02 .2005 & 01.03 .2005 & NEGATIVE \\
\hline $33 / 05$ & 07.02 .2004 & 15.02 .2005 & 01.03 .2005 & NEGATIVE \\
\hline
\end{tabular}

* repeated taking of sample with off-set

One month later epidemiologists from Topol'čany sent us four new nasopharyngeal swabs from other inhabitants of these flats and also two repeated swabs from two children (Table 4).

\section{METHODS}

Isolation of DNA from the sample: We have isolated the bacterial DNA using the High Pure PCR Template Kit (12) according to the manufacturer's protocol. We have used $5 \mu \mathrm{l}$ of isolated bacterial DNA for each of the reaction.

Two control swabs from epidemiologist were used as negative control of nucleic acid isolation.

Bordetella pertussis strain, CNCTC 5268, from collection of microorganisms, from the National Institute of Public in Prague, was used as positive control of nucleic acid isolation.

PCR: PCR was performed using the LightCycler PCR instrument, LighCycler software version 3.5.3 and the LightCycler Fast Start DNA Master Hybridization Probes Kit (13), all from Roche Diagnostics. The kit contains Taq DNA polymerase, $\mathrm{MgCl} 2$ solu-

Table 5. Primers and probes sequences

Bordetella pertussis repetitive insertion sequence IS481

\begin{tabular}{|l|c|r|}
\hline Bordetella pertussis repetitive insertion sequence IS481 & Length \\
\hline Primers & \multicolumn{2}{|c|}{ GC (\%) } \\
\hline GATTCAATAGGTTGTATGCATGGTT & 25 & 36.0 \\
\hline TTCAGGCACACAACTTGATGGGCG & 25 & 52.0 \\
\hline Probes & \multicolumn{2}{|c|}{} \\
\hline TCGCCAACCCCCCAGTTCACTCA- - F & 23 & 60.9 \\
\hline LCRed640- - AGCCCGGCCGGATGACACCC & 21 & 71.4 \\
\hline
\end{tabular}


Table 6. Master mix compositon

\begin{tabular}{|l|c|c|}
\hline & Volume $(\mu \mathrm{l})$ & Final concentration \\
\hline $\begin{array}{l}\text { LightCycler fast start DNA master } \\
\text { hybridization probes }(10 \mathrm{x})\end{array}$ & 2 & $1 \mathrm{x}$ \\
\hline $\mathrm{MgCl}_{2}$ stock solution $(25 \mathrm{mM})$ & 1.6 & $3 \mathrm{mM}$ \\
\hline Primers $(10 \mu \mathrm{M}$ each $)$ & $1+1$ & $0,5 \mu \mathrm{M}$ each \\
\hline Hybridization Probes $(2 \mu \mathrm{M}$ each) & $2+2$ & $0,2 \mu \mathrm{M}$ each \\
\hline PCR- grade water & 8.4 & \\
\hline Total volume & 18 & \\
\hline
\end{tabular}

tion, PCR-grade water and free nucleotides. Primers and probes were synthetized by TibMol Biol (Berlin, Germany) according to previous study (10). A previously published primer pair (5) and probes (10) (Table 5) were used for amplifying a segment within the Bordetella pertussis repetitive insertion sequence IS481, which proved to be a very sensitive target (10).

The following master mix was used for amplification and hybridization probe-based detection of the IS481 specific amplicons (Table 6).

To complete the amplification mixtures, $18 \mu \mathrm{l}$ of master mix and $2 \mu \mathrm{l}$ of the corresponding template DNA preparation were added to each capillary. After a short centrifugation (7sec/ 3000 $\mathrm{g}$ ), the sealed capillaries were placed into the LightCycler rotor.

The presence of IS481 of BP in clinical specimens was proven under identical reaction conditions, together with positive and negative controls. The reaction ran in the following steps $(10,14)$ :

Denaturation $10 \mathrm{~min}$ at $95{ }^{\circ} \mathrm{C}$. Amplification was done in 50 cycles. For one cycle there were the following conditions: $10 \mathrm{sec}$ at $95^{\circ} \mathrm{C}$ (denaturation), 10 sec at $50^{\circ} \mathrm{C}$ (annealing - application of primers and probes), 12 sec at $72^{\circ} \mathrm{C}$ (amplification-DNA synthesis).

Control of reaction: At the same time and under the same conditions, the control of procedure of PCR was inspected using the positive and negative controls. The negative control sample was prepared by replacing the DNA template with PCR-grade water. The positive control sample was prepared by adding $2 \mu \mathrm{l}$ of Bordetella pertussis genomic DNA (Bordetella pertussis strain, CNCTC 5268, from the National Institute of Public Health in Prague) to the master mix. The genomic DNA from this strain was isolate using High Pure PCR Template Isolation Kit (12), according to the manufacturer's manual.

Electrophoresis: After the completion of amplification in LightCycler instrument we have analysed products of amplification also by using electrophoresis in agarose gel (90V/ $20 \mathrm{~min})$.

\section{RESULTS AND DISCUSSION}

First according to author's protocol (10), we had to introduce this new diagnostic method for detection of Bordetella pertussis into the microbiology laboratory practice. Then this method was tested with reference sample which was the strain of Bordetella pertussis (CNCTC 5268, from collection of microorganisms, from the National Institute of Public Health in Prague). In the next step we confirmed the detection limit of this reaction, which was originally done by Reischel et al. (10) and it was 1 pg of DNA template.
We tested 33 nasopharyngeal swabs from 29 patients and 2 control swabs from epidemiologists, which we used as negative controls of nucleic acid isolation.

First laboratory confirmed case of whooping cough was reported from the little boy, born 01. 05. 2004, resident of Nitra. He suffered from a pertussis-like symptoms and the diagnosis was also confirmed because of uncompleted vaccination. First dose of vaccination was applied to him on 30. 08. 2004. He was sick from 02. 09. 2004.

From the beginning the affection had febrile progress $\left(38{ }^{\circ} \mathrm{C}\right)$ with graduated cough followed by vomiting. In the time of incubation period the boy stayed abroad. (Germany, Mannheim - 28. 07. 2004-09. 08. 2004). Doctors treated him by antibiotics for 17 days (Penbene+Zinat).

Epidemiologists found out that brother of this boy, born 20. 12. 1990, was in a contact with him all days. He had clinical symptoms of pertussis for longer time before, but his illness was not laboratory confirmed. His vaccination and revaccination was completed (DITEPER).

Next two laboratory confirmed cases of whooping cough pertussis were two sisters, neighbours of these two boys (brothers). One of them, born on 07. 01. 1991, was the first case of illness in a family and in the dwelling-place too. Probably she imported the illness from abroad because of her stay in Paris (01. 07. 200406. 07. 2004) and in Germany (Mannhiem 07. 07. 200408. 07. 2004). Ten days after arriving home she had typical clinical symptoms of pertussis. Her vaccination and revaccination was completed (DITEPER). She was treated by combination of antibiotics (Duracef, Ospamox, Zinnat).

Her sister, born on 12. 09. 1985, was the second case of illness in the family and in the dwelling-place too. This illness was also laboratory confirmed. Her vaccination and revaccination was completed (DITEPER). She was treated by Azitrox.

We did not succeed in obtaining the information on patients from Topolčany and about their vaccination and revaccination status.

Based on the analyses of increasing fluorescent curves at real-time PCR, the presence of IS481 of Bordetella pertussis in 22 nasopharyngeal swabs from 20 patients was not confirmed, however, the presence of Bordetella pertussis was confirmed in 10 nasopharyngeal swabs from 9 patients (F igs. 1-5, Tables 1-4). In one case the result was disputable, because the fluorescent curve

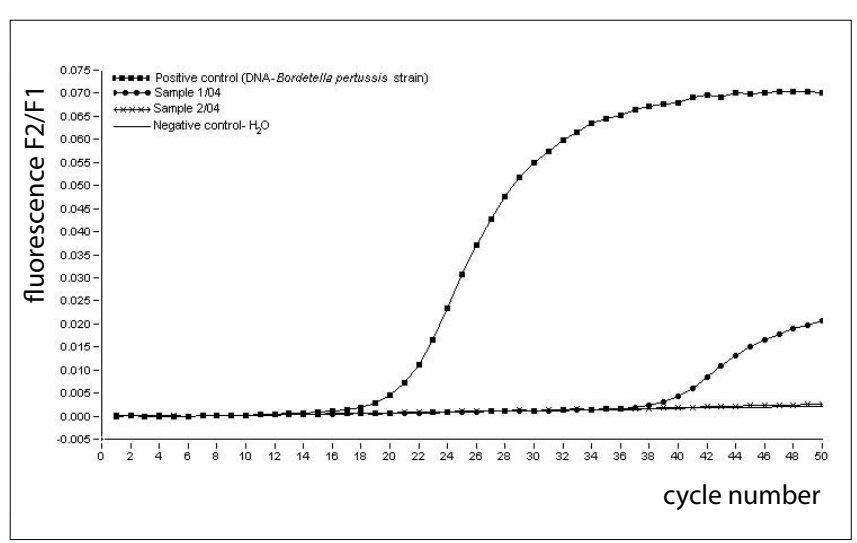

Fig. 1. Analysis of PCR. With growing number of cycles during amplification, values of fluorescence at some examinated sample (1/04) grow, what suggests presence of $B$. pertussis in examinated sample. 


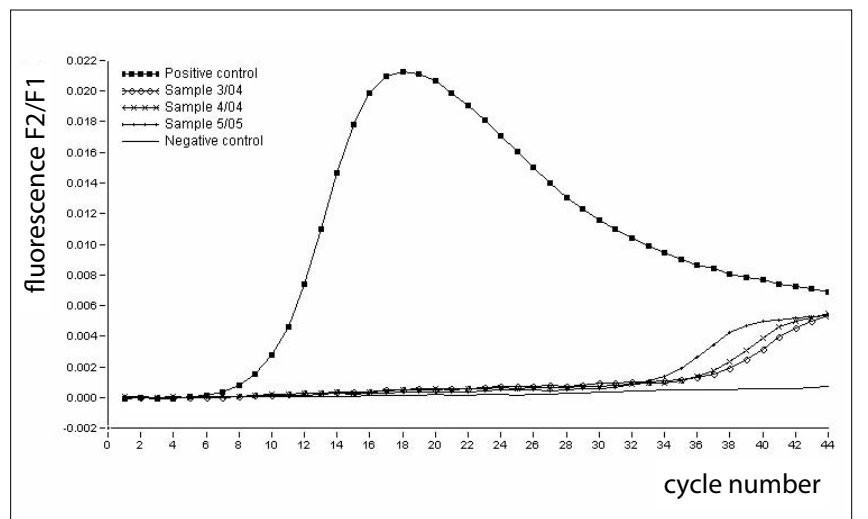

Fig. 2. Analysis of PCR. With growing number of cycles during amplification, values of fluorescence at some examinated samples grow, what suggests presence of $B$. pertussis in examinated samples.

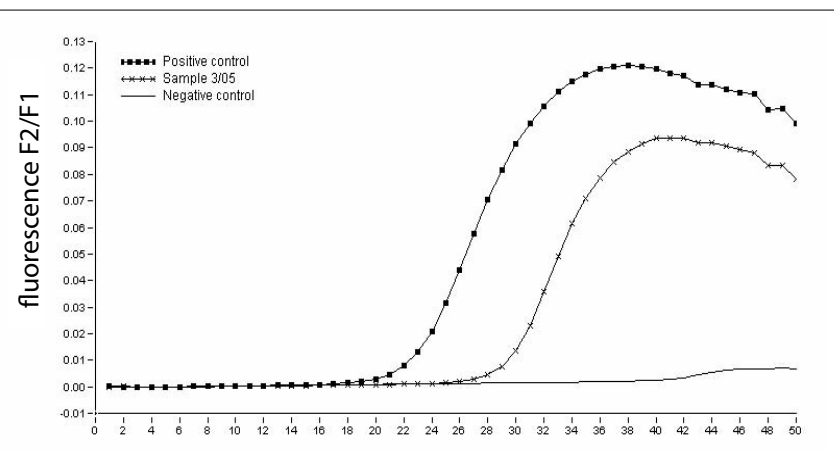

cycle number

Fig. 3. Analysis of PCR. With growing number of cycles during amplification, values of fluorescence at examinated sample grow, what suggests presence of $B$. pertussis in this sample. of this sample increased but after the electrophoresis there was no band on agarose gel (Table 2 - sample 26, Fig. 4). After diluting this sample the result was the same. This disputable case was nevertheless considered by doctors as positive because of presence of clinical symptoms of disease.

The presence of IS481 of Bordetella pertussis in two control nasopharyngeal swabs from two epidemiologists was not confirmed (Table 3, Fig. 4).

In repeated sample with off-set from little boy, residing in Topol'čany, the result was negative. It is possible that it was because of antibiotics administered to him.

Definitive diagnosis of causative organism in pertussis (whooping cough), Bordetella pertussis, is traditionally being made by culture of secretions from the nasopharynx (1). The sensitivity of this test is low, but the specificity is $100 \%$, the culture of BP until recently was the preferred method for diagnosing pertussis even though it takes $4-7$ days $(1,15,16)$.

Serological tests like KFR or ELISA (detection of antibodies produced against a filamentous hemaglutinin or against pertussis toxin) are more sensitive than culture, but these usually only provide late, or retrospective diagnosis (2).

Also direct antigen detection by a fluorescent antibody test and ELISA techniques have shown problems with specificity $(1,15$, 17). There are also two major drawbacks in diagnosing pertussis by serology: it cannot be used in acute phase of the disease, and it can be difficult to differentiate between vaccine effects and a pertussis infection (10).

To overcome these limitations, detection of $B$. pertussis DNA from nasopharyngeal aspirates and swabs has been described using PCR assays, including those targeting the promoter region of the gene encoding pertussis toxin S1 subunit (ptxA) $(3,4)$, the insertion element IS481 (5), the adenylate cyclase gene (cyaA) (6) and a region upstream of the outer-membrane porin gene (7). The best material for PCR testing method is a nasopharyngeal swab taking by dacron tampons because previous studies have shown

\footnotetext{
Sample 4/05

Sample $5 / 05$

Sample 6105

Sample 7/05

Sample 805 ring

Sample

Sample 9/05

Sample 10,05

Sample $12 j 05$

Sample 13/05 roor

Sample 14/05 -

Sample 15/05

Sample $16 / 05=$

Sample 17/05 --ー

Sample 18/05 $\cdots$

Sample 19/05 $9 \cdot-\theta \cdot 0$

Sample 20/05 $\{* * * * *$

Sample 21/05 ....**

Sample 22/05

Sample 23/05 r++++

Sample 24/05

Sample 25/05 -..

Sample 26/05 - -

Positive control

Negative controb-
}

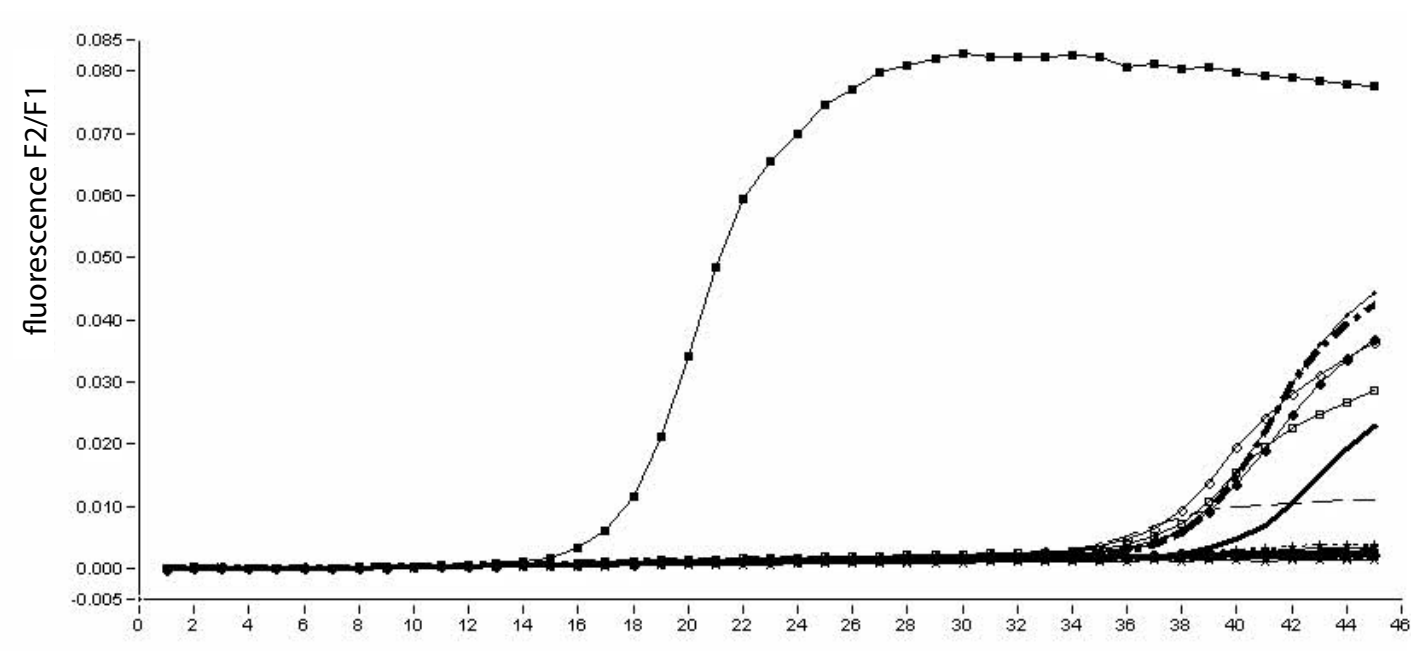

cycle number

Fig. 4. Analysis of PCR. With growing number of cycles during amplification, values of fluorescence at examinated sample grow, what suggests presence of $B$. pertussis in this sample. 
that calcium alginate fiber and aluminium shaft components inhibited PCR reaction (11).

In 2001 Kösters et al. have developed a real-time PCR assay based on the TaqMan technology for detection of Bordetella pertussis in clinical samples (9). One year later Reischel et al. have described a real-time PCR technique for detection of Bordetella pertussis by using LightCycler instrument and fluorescent labelled probes (10).

Using this method of detection it is also possible to distinguish between Bordetella pertussis and Bordetella parapertussis. The illness caused by $B$. parapertussis is usually milder than that caused by $B$. pertussis. Simultaneous infection with $B$. pertussis and $B$. parapertussis has been observed in clinical practice.

$B$. pertussis repetitive insertion sequence IS481 and B. parapertussis repetitive insertion sequence IS1001 were selected as targets for the duplex PCR (10).

Real-time PCR compared to conventional PCR has several advantages: (i) compared to conventional PCR, preparation, pretreatment of sample and processing of reaction are simplified and require far less time (time required for detection is shortened from cca 8 hours to cca 3 hours); (ii) the reaction runs in closed system of glass capillaries, which significantly reduces the possibility of any contamination of analytical sample; (iii) it has a broad spectrum of application, such as the possibility to detect mutations and deletions, analysis of gene expression in the molecular oncology, and others; and (iv) the possibilities to detect pathogens, which are impossible or difficult to cultivate, or they occur in such a small quantity that they cannot be detected by other methods $(10,18)$. Recent studies $(3,5,19)$ suggest that PCR based assays and real-time PCR based assays $(9,10)$ are more sensitive than culture for detection of Bordetella pertussis in nasopharyngeal specimens. Serological methods have shown low sensitivity and specificity too $(1,17)$. The PCR based assays give us relevant results till few hours, whereas final isolation and identification with culture generally take 3 to 5 days.

Some studies $(20,21,22,23)$ show to significant crossreactivity of IS481 based PCR assays with Bordetella holmesii genomic DNA. But from the clinical point of view, however, the risk of $B$. holmesii giving false positive results by $B$. pertussis IS481 PCR should be minimal because up to now it was found only sporadically in patients with respiratory symptoms $(10,21)$. B. holmesii accounted for less than $4 \%$ of Bordetella spp. cultured from patients with pertussis-like illness $(23,24)$.

IS481 based PCR assays could be considered as a valuable addition to pertussis diagnostic testing (10).

Bordetella pertussis is a rare disease in this time so we found these cases clinically and epidemiologically very interesting.

\section{CONCLUSION}

In conclusion we consider PCR and real-time PCR based assays to be suitable methods for clinical and epidemiological practice and are also an efficient tool for prevention of epidemic and avoiding negative results due to administered antibiotics.

Moreover, the real-time PCR based assays have some advantages over classical detection methods (cultivation and serology) and conventional PCR based assays, too. It eliminates the need for post-amplification handling, thereby reducing the risk of contamination and also decreases total analysis time $(18,25)$.

The laboratories equipped with these techniques and possibilities really poses a useful and efficient tool for the prevention and therapy of infection disease.

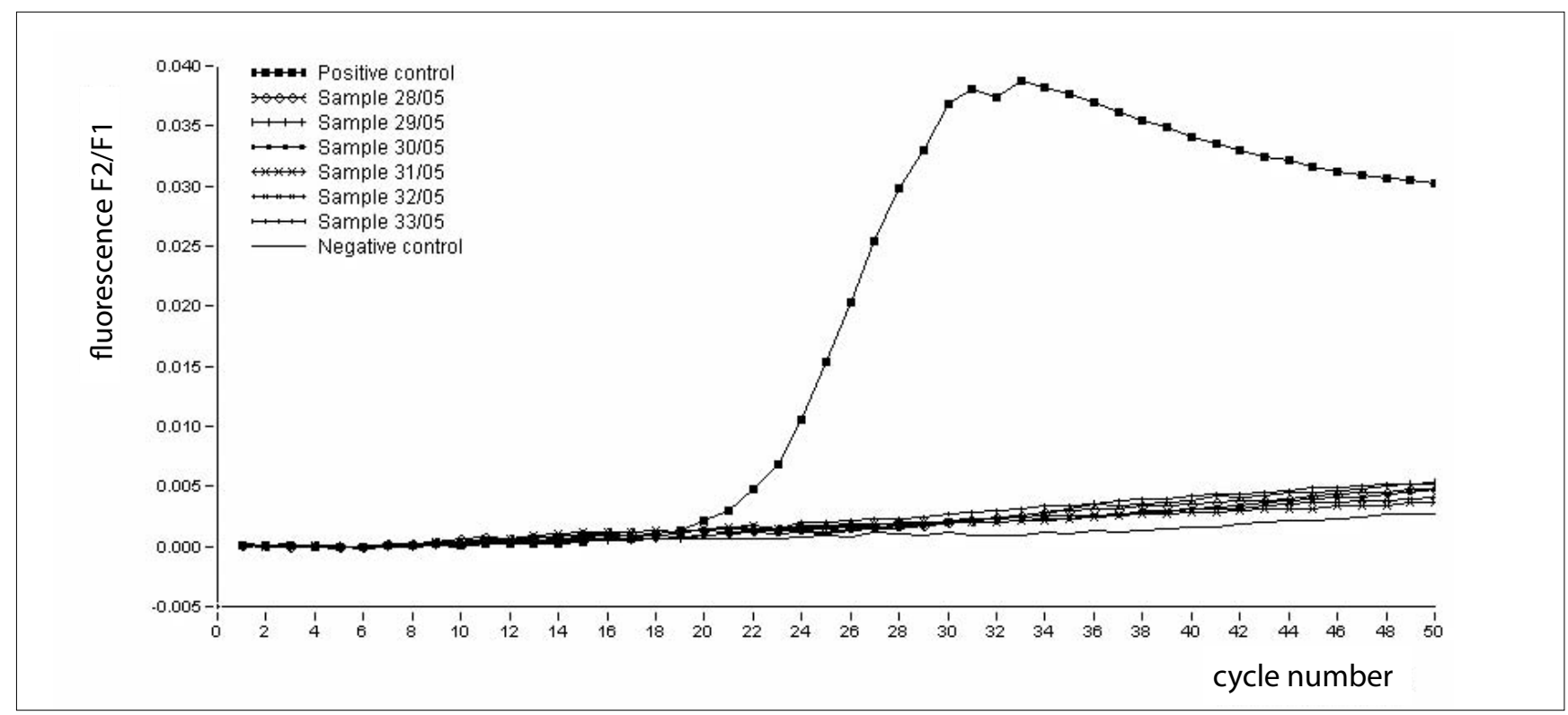

Fig. 5. Analysis of PCR. With growing number of cycles during amplification, values of fluorescence at the examinated samples did not grow, examinated samples are negative. 


\section{REFERENCES}

1. Onorato IM, Wassilak SG. Laboratory diagnosis of pertussis: the state of the art. Pediatr Infect Dis J. 1987 Feb;6(2):145-51.

2. Kerr JR, Matthews RC. Bordetella pertussis infection: pathogenesis, diagnosis, management, and the role of protective immunity. Eur J Clin Microbiol Infect Dis. 2000 Feb;19(2):77-88.

3. Hourd S, Hackelc C, Herzog A, Bollen A. Specific identification of Bordetella pertussis by the polymerase chain reaction. Res Microbiol. 1989 Sep;140(7):477-87.

4. Mastrantonio P, Stefanelli P, Giuliano M. Polymerase chain reaction for the detection of Bordetella pertussis in clinical nasopharyngeal aspirates. J Med Microbiol. 1996 Apr;44(4):261-6.

5. Glare EM, Paton JC, Premier RR, Lawrence AJ, Nisbet IT. Analysis of a repetitive DNA sequence from Bordetella pertussis and its application to the diagnosis of pertussis using the polymerase chain reaction. J Clin Microbiol. 1990 Sep;28(9):1982-7.

6. Douglas E, Coote JG, Parton R, McPheat W. Identification of Bordetella pertussis in nasopharyngeal swabs by PCR amplification of a region of the adenylate cyclase gene. J Med Microbiol. 1993 Feb;38(2):140-4.

7. Li Z, Jansen DL, Finn TM, Halperin SA, Kasina A, O'Connor SP, et al. Identification of Bordetella pertussis infection by shared-primer PCR. J Clin Microbiol. 1994 Mar;32(3):783-9.

8. Olcen P, Backman A, Johansson B, Esbjorner E, Torquist E, Bygraves, J., et al. Amplification of DNA by the polymerase chain reaction for the efficient diagnosis of pertussis. Scand J Infect Dis. 1992;24(3):339-45.

9. Kosters K, Riffelmann M, Wirsing von Konig CH. Evaluation of a realtime PCR assay for detection of Bordetella pertussis and B. parapertussis in clinical samples. J Med Microbiol. 2001 May;50(5):436-40.

10. Reischel U, Kosters K, Leppmeier B, Linde HJ, Lehn N. Rapid Detection and Simultaneous Differentiation of Bordetella pertussis and Bordetella parapertussis in Clinical Specimans by LightCycler PCR. In: Reischl U, Wittwer C, Cockerill F, editors. Rapid Cycle Rel-Time PCR-Methods and Applications. Berlin: Springer Verlag; 2002. p. 31-43.

11. Wadowski RM, Laus S, Libert T, States SJ, Ehrlich GD. Inhibition of PCR-based assay for Bordetella pertussis by using calcium alginate fiber and aluminum shaft components of a nasopharyngeal swab. J Clin Microbiol. 1994 Apr;32(4):1054-7.

12. Roche Diagnostics GmbH. High Pure PCR Template Preparation Kit. Instruction Manual. March 2002.
13. Roche Diagnostics GmbH. LightCycler Fast Start DNA Master Hybridization Probes. Instruction Manual. November 2001

14. Roche Diagnostics GmbH. PCR Applications Manual. 2nd ed. Mannheim: 1999.

15. Birkebaek NH, Heron I, Skjodt K. Bordetella pertussis diagnosed by polymerase chain reaction. Bordetella pertussis diagnosed by polymerase chain reaction. APMIS. 1994 Apr;102(4):291-4.

16. Fry NK, Tzivra O, Li YT, McNiff A, Doshi N, Maple PA, et al. Laboratory diagnosis of pertussis infections: the role of PCR and serology. J Med Microbiol. 2004 Jun;53:519-25.

17. Storsaeter J. Studies of the protective efficacy of two acellular pertussis vaccines. Stockholm: Thesis, 1991.

18. Žúrek D. Usefulness of real-time PCR in laboratory diagnosis. Laboratórna diagnostika. 2003;8(1):50-1. (In Czech.)

19. He Q, Mertsola J, Soini H, Skurnik M, Ruuskanen O, Viljanen MK. Comparison of polymerase chain reaction with culture and enzyme immunoassay for diagnosis of pertussis. J Clin Microbiol. 1993 Mar;31(3):6425 .

20. Lind-Brandberg L, Welinder-Olsson C, Lagergard T, Taranger J, Trollfors B, Zackrisson G. Evaluation of PCR for diagnosis of Bordetella pertussis and Bordetella parapertussis infections. J Clin Microbiol. 1998 Mar;36(3):679-83.

21. Yih WK, Silva EA, Ida J, Harrington N, Lett SM, George H. Bordetella holmesii-like organisms isolated from Massachusetts patients with pertussis-like symptoms. Emerg Infect Dis. 1999 May-Jun;5(3):441-3.

22. Loeffelholz MJ, Thompson CJ, Long KS, Gilchrist MJ. Detection of Bordetella holmesii using Bordetella pertussis IS481 PCR assay. J Clin Microbiol. 2000 Jan;38(1):467.

23. Reischl U, Lehn N, Sanden GN, Loeffelholz MJ. Real-time PCR assay targeting IS481 of Bordetella pertussis and molecular basis for detecting Bordetella holmesii. J Clin Microbiol. 2001 May;39(5):1963-6.

24. Mazengia E, Silva EA, Peppe JA, Timperi R, George H. Recovery of Bordetella holmesii from patients with pertussis-like symptoms: use of pulsed-field gel electrophoresis to characterize circulating strains. J Clin Microbiol. 2000 Jun;38(6):2330-3.

25. Dókušová L, Sirági P, Klement C, Schréter I, Kristian P, Jarčuška P., et al. Confirmation of anthrax occurrence using real-time PCR. Biologia, Bratislava. 2004;59(6):797-801.

Received June 8, 2006

Received in revised form and accepted October 17, 2006 